\title{
CONCEITO DE LIBERDADE EM ARISTÓTELES E NO EXISTENCIALISMO SARTREANO
}

CONCEPT OF LIBERTY IN ARISTÓTELES AND IN SARTREAN EXISTENNIALISM

Rodrigo Alves Zaparoli ${ }^{1}$

\section{RESUMO}

O presente trabalho almeja analisar o conceito de liberdade segundo as teorias criadas pelos filósofos Aristóteles e Jean Paul Sartre. O estudo proposto levará em consideração a sociedade em que os filósofos estavam inseridos, bem como suas principais produções literárias aptas a tratar do assunto.

Palavras-chave: Aristóteles. Jean Paul Sartre. Liberdade.

\section{ABSTRACT}

The present work aims to analyze the concept of freedom according to the theories created by the philosophers Aristotle and Jean Paul Sartre. The proposed study will take into account the society in which the philoso-

\footnotetext{
1 Advogado; Mestrando em Direito Civil Comparado pela Pontifícia Universidade Católica de São Paulo; Especialista em Direito Civil pela Universidade Presbiteriana Mackenzie; Graduado em Direito pela Universidade Presbiteriana Mackenzie.
} 
phers were inserted, as well as their main literary productions able to deal with the subject.

Keywords: Aristotle. Jean Paul Sartre. Freedom.

\section{INTRODUÇÃO}

O presente trabalho possui o escopo de discorrer sobre o conceito de liberdade pautando-se nas teorias criadas pelos filósofos Aristóteles e Jean Paul Sartre.

Vale ressaltar que a restrição ao tema aos filósofos acima descritos se faz indispensável, pois apresentar um conceito universal de liberdade revela-se como uma tarefa trabalhosa e praticamente impossível, já que seu âmbito de aplicação apresenta-se de forma ilimitada.

Insta salientar que as questões atreladas ao campo de aplicação da liberdade alastram-se por diversos segmentos, circunstância comprovada ao se constatar que incontáveis teorias desenvolvidas em períodos distintos da humanidade tiveram o objetivo de apresentar um conceito pleno de liberdade, estudos estes que muitas vezes transcenderam a ciência da filosofia, pautando-se na biologia, psicologia, dentre outras ciências para justificar suas razões.

Por sua vez, é necessário discorrer também sobre a origem etimológica da palavra liberdade, que provém do vocábulo libertas, que fora empregado para diferenciar os cidadãos das demais pessoas que não possuíam a faculdade de exercer sua liberdade de maneira plena, circunstância que ocorria, por exemplo, com os escravos na Grécia e Roma Antiga.

Ainda com relação à origem histórica etimológica da palavra liberdade, relevantes se demonstram os ensinamentos expressos por Miguel Reale, que declara:

(...) Se nos limitarmos ao mundo clássico, podemos verificar que nem todos os homens foram tidos como pessoas, ou titulares de direitos. Havia escravos e homens livres. A idéia mesmo de liberdade civil, que nos parece conatural ao homem, pelo simples fato de ser homem, tinha um valor secundário resultante de uma situação política. $\mathrm{O}$ grego ou o romano não eram livres por serem homens, mas sim, por serem 
cidadãos de Atenas ou de Roma. O status libertatis era uma decorrência do status civitatis. $\mathrm{O}$ ateniense e o romano deviam, em primeiro lugar, satisfazer a certos requisitos de pertinência à sua cidade politicamente organizada, ou seja, à polis ou a civitas romana $(\ldots)^{2}$

Ante os fatos narrados, observa-se que o conceito de liberdade foi submetido a transformações no curso dos anos, alterações que foram motivadas principalmente pelo contexto econômico, político, religioso e social que o ser humano vivenciava.

Portanto, através do presente estudo analisar-se-á em um primeiro momento o conceito de liberdade criado por Aristóteles, levando-se em consideração inclusive o contexto social vivenciado pelo filósofo grego.

Após a análise supracitada, será realizado um estudo aprofundado acerca da liberdade na doutrina existencialista criada por Jean Paul Sartre.

Sendo assim, diante da amplitude relacionada ao tema liberdade, focalizar-se-ão as pesquisas ao estudo do conceito de liberdade em Aristóteles e no existencialismo de Jean Paul Sartre.

\section{CONCEITO DE LIBERDADE EM ARISTÓTELES}

A primeira teoria filosófica que se demonstrou relevante a versar sobre a liberdade foi desenvolvida por Aristóteles.

Vale ressaltar que o filósofo grego desenvolveu a teoria supracitada através de sua obra Ética a Nicômaco, que abordou o tema ao discorrer sobre os modos de liberdade.

Insta salientar que a sociedade grega do período em análise destacou-se por visualizar a importância do homem, tanto no âmbito estadual quanto no universal, vez que os gregos foram os responsáveis por conceber a igualdade entre as pessoas baseando-se no respeito a uma legislação de aplicação geral.

${ }^{2}$ REALE, Miguel. Lições preliminares de direito, 27ª ed. São Paulo: Saraiva, 2002, p. 228. 
Além do mais, a civilização grega mantinha em seu cotidiano a prática da escravidão, bem como da desigualdade política, já que os direitos políticos eram concedidos apenas aos considerados cidadãos, que consistiam somente nas pessoas nascidas em Atenas, do sexo masculino e maiores de vinte anos, logo, permaneciam excluídos do processo decisório as mulheres, estrangeiros e escravos.

Findada a breve exposição acerca do contexto social e político vivenciado na Grécia Antiga, será retomado o estudo atrelado à análise do conceito de liberdade para o filósofo grego.

Cumpre esclarecer que, através de sua doutrina, Aristóteles sustenta que é considerado livre aquele que apresenta em si mesmo o princípio norteador que o impulsiona a agir ou não agir, ou seja, a ideia de liberdade estaria vinculada ao ser como causa interna de sua própria ação ou omissão.

Além do mais, o filósofo grego defende o entendimento de que do mesmo modo de que uma ação boa depende de seu agente, também, em idêntica proporção de escolha, dependerá do autor da ação a não realização de um ato maléfico.

Dessa forma, observa-se que segundo a doutrina aristotélica, a liberdade seria considerada como o poder incondicional da vontade para que essa viesse a ser determinada em si mesma.

Em complementação ao que foi exposto, destaca-se que para Aristóteles a liberdade também é avaliada como a ausência de interferências externas e internas na ação ou omissão exercida pelo titular da liberdade.

Portanto, ao se analisar o que foi exposto no parágrafo acima, constata-se que a liberdade para Aristóteles não encontraria obstáculos para ser desenvolvida, circunstância que engloba inclusive o fato de que o exercício da liberdade não poderia ser constrangido em hipótese alguma.

Ante as considerações ofertadas, pode-se afirmar que, de acordo com o pensamento aristotélico, o detentor da liberdade não poderá ser coagido a exercê-la, pois o exercício estaria vinculado a uma ação, ou ainda, a uma inércia por parte do titular desse livre arbítrio.

Aristóteles sustenta ainda que a ação moral do homem encontrase vinculada diretamente com a liberdade da vontade, logo, seria a ação voluntária responsável por implicar em uma liberdade de escolha por parte de seu agente. 
Diante do exposto, pode-se constatar que para o filósofo grego a liberdade consistiria na espontaneidade absoluta de seu titular, que fornecerá a si mesmo as razões e finalidades para o exercício de suas ações e omissões, sem que ocorra qualquer espécie de constrangimento ou coação.

Assim, a liberdade, através de seu livre exercício, permitiria a eleição entre múltiplas alternativas possíveis, realizando-se através de uma decisão, ou ainda, de um ato voluntário.

Com o escopo de se facilitar a compreensão da matéria, serão focalizadas as lições ofertadas por Aristóteles, que, ao discorrer sobre ações voluntárias, estabelece:

(...) quando tem em si próprio o princípio (motivador) da ação, acionando assim os elementos instrumentais da ação. Quando o princípio motivador se encontra no próprio agente, é dele que depende o serem levadas à prática ou não. Ações deste gênero são, pois, voluntárias, mesmo que resultem da força das circunstâncias. ${ }^{3}$

Além do mais, durante a construção de sua teoria acerca da liberdade, o filósofo grego também se presta a diferenciar a ação voluntária, daquela que se revela como diretamente oposta.

Insta salientar que em oposição às ações voluntárias, apresentam-se as involuntárias, que, segundo Aristóteles, consistem naquelas realizadas "sob coação ou por ignorância. Um ato perpetrado sob coação é aquele cujo princípio (motivador) lhe é extrínseco." 4

Expostos os conceitos inerentes às ações voluntárias e involuntárias, necessário se faz apresentar também a definição do que seriam decisões. Aristóteles dispõe sobre o tema:

Uma decisão parece tratar-se de um ato voluntário, mas nem todo o ato voluntário parece ter de resultar de uma decisão. Implicará, então, uma decisão

${ }^{3}$ ARISTÓTELES. Ética a Nicômaco; Tradução do grego de António de Castro Caeiro. São Paulo: Atlas, 2009, p. 57.

${ }^{4}$ Ibidem, p. 56. 
sempre uma deliberação prévia? Na verdade, uma decisão implica um sentido orientador e um processo de pensamento. É o que parece também deixar entender o nome, como sendo uma escolha preferida em detrimento de outras preteridas. ${ }^{5}$

Diante dos ensinamentos transcritos, resta incontroverso que por meio do exercício da liberdade serão proferidas decisões, ou ainda, desenvolvidos atos voluntários, que se prestarão a escolher uma alternativa entre as diversas que se apresentam ao titular da liberdade.

Relevante também se faz informar, que, ao discorrer sobre a liberdade, Aristóteles versa sobre a distinção existente entre o necessário e o contingente, bem como traça as diferenças presentes entre o contingente e o possível.

Ao tecer comentários sobre o tema, Marilena Chaui, leciona:

Além de distinguir entre $\mathrm{o}$ necessário e $\mathrm{o}$ contingente, Aristóteles também distingue entre o contingente e o possível: o primeiro é o puro acaso, mas o segundo é o que pode acontecer desde que um ser humano delibere e decida realizar uma ação. Assim, na concepção aristotélica, a liberdade é o princípio para escolher entre alternativas possíveis, realizando-se como decisão e ato voluntário. Contrariamente ao necessário ou à necessidade e à contingência, sob as quais o agente sofre a ação de uma causa externa que o obriga a agir de uma determinada maneira, no ato voluntário livre o agente é causa de si (...). ${ }^{6}$

Assim, de acordo com a teoria formulada por Aristóteles a liberdade consistiria no princípio apto e eficaz para eleger dentre as alternativas existentes qual será a praticada, destacando-se que todas as coisas tenderão a uma finalidade, sendo que esse fim poderá ser reduzido à felicidade.

${ }^{5}$ ARISTÓTELES. Ética a Nicômaco; Tradução do grego de António de Castro Caeiro. São Paulo: Atlas, 2009, p. 62.

${ }^{6}$ CHAUI, Marilena. Convite à filosofia. São Paulo: Ática, 2012, p. 415 e 416. 
Ao discorrer sobre a felicidade, Aristóteles a conceitua da seguinte maneira:

(...) procuremos compreender, agora - uma vez que todo o saber e toda a intenção têm um bem por que anseiam -, o que dissemos sobre a perícia política e o que ela visa atingir bem como sobre qual será o mais extremo dos bens susceptível de ser obtido pela ação humana. Quanto ao nome desse bem, parece haver acordo entre a maioria dos homens. Tanto a maioria como os mais sofisticados dizem ser a felicidade, porque supõem que ser feliz é o mesmo que viver bem e passar bem. ${ }^{7}$

Sendo assim, ao se analisar o que foi abordado até o momento, conclui-se que o exercício da liberdade, que se perpetua através da escolha das alternativas existentes, que acabam por se desenvolver por meio das decisões e dos atos voluntários, revela-se contrário ao necessário e à contingência.

Insta salientar que nos casos em que se evidencia o necessário e a contingência, o titular da liberdade acaba por sofrer com a incidência de uma motivação exterior, que o obrigará a atuar de uma forma determinada.

Por sua vez, observa-se ainda, que na prática do ato voluntário livre, o detentor da liberdade se apresenta como a própria causa de si.

Cumpre esclarecer que ao se considerar o titular da liberdade como a causa de si, acaba-se por reconhecê-lo como a motivação integral de sua ação, circunstância que permitiria entender que o ato voluntário livre seria determinado pela própria razão do detentor da liberdade.

Em complementação ao que foi abordado, ao acatar a figura do homem livre como o princípio de si mesmo, Aristóteles o visualiza como possuidor da faculdade de decidir sobre temas que dependam diretamente dele, ou ainda, que possam ser por ele desenvolvidos, inserindo como agente a faculdade de se deliberar sobre todas as questões.

${ }^{7}$ ARISTÓTELES. Ética a Nicômaco; Tradução do grego de António de Castro Caeiro. São Paulo: Atlas, 2009, p. 20. 
Vale ressaltar que ao ventilar sobre quais são as deliberações do homem, Aristóteles afirma que "deliberamos sobre aquelas coisas que nos dizem respeito e que dependem de nós, a saber sobre as ações que podem ser praticadas por nós". ${ }^{8}$

Destaca-se ainda, que segundo Aristóteles, "Deliberamos, assim, não sobre os fins, mas sobre os meios de os atingirmos (...) Assim, o fim não poderá nunca ser objeto de deliberação, apenas o são os meios em vista de sua obtenção". ${ }^{9}$

Além do mais, ao declarar que o ato voluntário livre é norteado pela própria motivação do titular da liberdade, revela-se necessário admitir que tal ato não será algo incondicionado, mas sim fruto do próprio raciocínio e inteligência de seu detentor.

Todavia, necessário se faz informar que a inteligência supracitada acaba de certa maneira por direcionar a vontade do agente para um determinado caminho, entretanto, tal direcionamento não o obrigará nem mesmo lhe causará constrangimento.

A declaração acima se fundamenta pelo simples fato de que o titular da liberdade, responsável pela eleição de suas possibilidades poderá agir de maneira contrária àquela que lhe foi norteada por sua inteligência ou razão.

Ao discorrer sobre o tema, Aristóteles declara:

(...) quando está no nosso poder dizer não também está no nosso poder dizer sim. De tal sorte assim é que se estiver no nosso poder o agir bem também estará o não agir vergonhosamente. Inversamente, se estiver no nosso poder não agir bem, também aí estará o agir vergonhosamente. Se está no nosso poder fazer coisas boas e vergonhosas, também está no nosso poder não as fazer. É nisto que consiste o poder ser bom ou mau. ${ }^{10}$

Portanto, ao observar o que foi abordado na transcrição acima, é possível afirmar que o titular da liberdade deverá sempre estar atento para

\footnotetext{
${ }^{8}$ ARISTÓTELES. Ética a Nicômaco; Tradução do grego de António de Castro Caeiro. São Paulo: Atlas, 2009, p. 20.

${ }^{9}$ Ibidem.

${ }^{10}$ Ibidem. p. 65 e 66.
} 
evitar os extremos condenáveis, circunstância que lhe permitirá a busca e manutenção do equilíbrio, também denominado meio-termo.

Sendo assim, restaram apresentadas as principais questões inerentes ao estudo da liberdade segundo Aristóteles, ocasião em que foi possível constatar que a teoria criada pelo filósofo grego se desenvolveu basicamente em um cenário político e social em que era comum a escravidão, bem como a restrição aos direitos de participação política.

Por fim, salienta-se também que a liberdade segundo Aristóteles facultava aos cidadãos gregos uma interação harmoniosa desses indivíduos com a sociedade em que viviam, destacando-se que o exercício da liberdade estaria vinculado à ação moral, que almeja a busca pela felicidade, que seria perseguida pelo ser humano através de suas ações voluntárias.

\section{CONCEITO DE LIBERDADE NO EXISTENCIALISMO DE JEAN PAUL SARTRE}

Superados os estudos inerentes à liberdade segundo Aristóteles, passa-se a analisar o conceito de liberdade para Jean Paul Sartre, filósofo francês que ganhou notoriedade pela construção de sua doutrina existencialista, que ao discorrer sobre o ser humano estabelecia que o "homem nada mais é do que aquilo que ele faz a si mesmo: é esse o primeiro princípio do existencialismo". ${ }^{11}$

Vale ressaltar que o existencialismo sartreano emanou com mais força após a Segunda Guerra Mundial, sendo caracterizado por ser uma teoria em que o homem possui plena responsabilidade por suas escolhas.

Insta salientar que o filósofo francês empregou na construção de sua doutrina experiências desfrutadas durante sua vida, destacando-se dentre elas aquelas que lhe marcaram por retirar-lhe o pleno exercício da liberdade.

\footnotetext{
${ }^{11}$ SARTRE, Jean Paul. O existencialismo é um humanismo. A imaginação: Questão de método. Seleção de textos de José Américo Motta Pessanha. Tradução de Rita Correira Guedes, Luiz Roberto Salinas Forte, Bento Prado Júnior. $3^{\text {a }}$ ed. São Paulo: Nova Cultural, 1987 , p. 06.
} 
Dentre as experiências supracitadas, destaca-se o fato de Jean Paul Sartre ter combatido na Segunda Guerra Mundial, ocasião em que chegou a ser capturado pelo exército nazista e transportado para um campo de concentração, momento que lhe proporcionou inúmeros diálogos com os demais prisioneiros, circunstância que lhe permitiu entender de forma pormenorizada qual seria o significado da liberdade para o ser humano.

Relevante também se apresenta a experiência vivenciada pelo filósofo francês de lutar pela liberdade de seu país, que, à época, encontrava-se ocupado pelas tropas nazistas, fatos que instigaram o filósofo a se manter próximo à sociedade que lhe cercava, bem como lhe auxiliou a buscar métodos de criação que pudessem ser disseminados de forma simples, porém, eficaz.

Cumpre esclarecer que o existencialismo sartreano adotava a presença da liberdade como algo essencial e inerente ao ser humano, vez que por intermédio do exercício de sua liberdade seria tal homem formado para o mundo.

Ao tecer comentários sobre a liberdade inerente ao homem, Luiz Damon Santos Moutinho, leciona que para Jean Paul Sartre a "liberdade não é uma propriedade do homem, como a de ser bípede, não é uma entidade metafísica cravada no seu espírito. Ao contrário, é o ser mesmo do homem, sempre engajado". ${ }^{12}$

Portanto, de acordo com a teoria existencialista sartreana, a liberdade consistiria na escolha incondicional que o próprio ser humano realiza acerca de seu ser, bem como do mundo em que habita.

Salientamos que os estudos formulados pelo filósofo francês acerca da liberdade ganharam notoriedade justamente pelo fato de que Jean Paul Sartre acabou por criar uma visão praticamente inédita acerca da liberdade humana.

Necessário se faz esclarecer que o ineditismo da teoria sartreana reside no fato de que segundo o entendimento criado pelo filósofo, o homem consiste na liberdade e está condenado a ela de modo eterno.

Assim, Jean Paul Sartre acaba por acatar o entendimento de que não existiria mais uma liberdade interna e outra externa, mas sim uma

12 MOUTINHO, Luiz Damon Santos. Sartre: existencialismo e liberdade. São Paulo: Moderna, 1995, p. 75. 
única liberdade que seria a principal responsável pela construção do ser humano.

Dessa maneira, a liberdade segundo o filósofo francês fundamenta-se basicamente na faculdade inerente ao homem de construir livremente seus caminhos, sendo caracterizada por se tratar de uma teoria em que o homem possui plena responsabilidade por suas escolhas.

A afirmação vinculada ao fato do ser humano ser o único responsável pela escolha de seu futuro fundamenta-se através do próprio existencialismo sartreano, vez que tal doutrina é caracterizada pelo fato da existência preceder a essência.

Importante se faz esclarecer que ao pautar-se no fato de que a existência precede a essência, o filósofo francês declara expressamente que o ser humano é dotado de uma liberdade plena.

Ao declarar que a liberdade humana é plena, Jean Paul Sartre afirma que o homem no exercício de sua liberdade não sofrerá qualquer espécie de limitação, a não ser aquela imposta por sua própria liberdade.

Assim, conclui-se que pelo fato da existência preceder a essência, o homem passa a existir para o mundo, ocasião em que começa a se descobrir e aparecer para os demais, momento este após aparecer ao mundo que será caracterizado pela definição do ser humano, logo, a existência antecederá e ordenará a essência.

Diante das considerações elencadas pode-se afirmar que, para o existencialismo sartreano, o homem inserido no mundo estará condenado a ser livre, circunstância que sempre lhe obrigará a escolher com forte carga de responsabilidade. Logo, o simples fato do homem decidir por permanecer inerte já resultaria em uma escolha.

Importante se faz destacar que o entendimento supracitado esteve expresso na obra de Jean Paul Sartre, que ao escrever O ser e o nada declarou: "liberdade é liberdade de escolher-se, mas não liberdade de não escolher. Com efeito, não escolher é escolher não escolher". ${ }^{13}$

Relevante se faz destacar, que o conceito de liberdade sartreano apresenta-se de grande valia também pelo fato de impor ao titular da liberdade a consciência de que responderá por seus atos, bem como pelos efeitos que tais ações ou omissões poderão gerar perante terceiros.

${ }^{13}$ SARTRE, Jean Paul. O ser e o nada: ensaio de ontologia fenomenológica. Tradução de Paulo Perdigão: Petrópolis, Vozes, 1998, p. 592. 
Todavia, apesar de impor ao ser humano o senso de responsabilidade narrado, a doutrina criada pelo filósofo francês também exclui do homem o pensamento de que por força da intervenção de um ser superior, ou ainda, simplesmente do acaso, seria obrigado a viver submetido a certas condições imutáveis, logo, a inexistência de seres superiores criadores e provedores do homem, proporcionaria tranquilidade ao ser humano, que teria total consciência de que sua vida seria passível de alteração a qualquer instante, bastando apenas que o próprio agente passe a se esforçar e percorrer novos rumos para efetuar as escolhas adequadas para a realidade que vive, ou, que pretende viver.

Diante da visão exposta, pode-se entender que o homem consiste apenas em um ser lançado ao mundo, em que não existe a figura de um Deus criador, circunstância que lhe faculta caminhar em diversos rumos, sem deixar de ser responsável pelo todo.

Logo, segundo a teoria existencialista sartreana, o homem não consiste em um objeto criado por um ser transcendental, mas sim, apresenta-se como alguém que surge para o mundo e através do viver nesse local se forma, transforma e define sob todos os aspectos.

Ao interpretar os dados fornecidos no parágrafo acima, constata-se que a liberdade não reside no poder, mas sim no livre querer, pois o homem será livre para edificar seus valores, até mesmo pelo fato de que inexistem valores universais diante da inexistência de um Deus criador.

Jean Paul Sartre destaca ainda que essa condição do homem ser responsável por suas ações, bem como pelas dos demais seres que constituem seu universo, já que acredita que as escolhas efetuadas pelo homem virão a repercutir sobre toda a coletividade, retrata o homem como um legislador.

Vale ressaltar que ao visualizar o ser humano como legislador, entende-se que esse acaba por decidir por si e por todos, destacando-se inclusive o fato de que o homem não possuirá algo ou alguém que valide suas atitudes, estando sempre condenado a sua própria escolha.

A informação acima prescrita pode ser justificada através de lições confeccionadas pelo filósofo francês, que ao discorrer sobre a escolha dos caminhos que poderão ser seguidos pelo homem, debate sobre a possibilidade do ser humano tornar-se covarde ou herói. Dispõe Jean Paul Sartre: "o existencialismo afirma é que o covarde se faz covarde que o 
herói se faz herói; existe sempre, para o covarde, uma possibilidade de não mais ser covarde, e, para o herói, de deixar de o ser". ${ }^{14}$

Portanto, baseados na doutrina existencialista sartreana, pode-se afirmar que o homem não é apenas aquilo que almeja ser, mas sim, fruto do projeto que está desenvolvendo, e que, além de se construir como ser humano, influenciará toda a humanidade direta ou indiretamente.

Desse modo, observa-se que a teoria existencialista desenvolvida por Jean Paul Sartre entende que o ser humano se resumirá à possibilidade de tomar decisões, sendo que a realização dessas escolhas se apresenta como essencial à formação do homem, que de acordo com o que foi estudado encontra-se no mundo para ser constantemente construído.

Ao tecer comentários sobre o fato de que as escolhas eleitas pelo homem são as responsáveis por construí-lo, Mônica Marcondes de Oliveira Santos, pautando-se nos ensinamentos criados por Jean Paul Sartre, leciona que: "a vida é permanente escolha e através de cada decisão nossa, definimos a nós mesmos por nós mesmos. A cada instante optamos por um valor, uma regra e conduta". ${ }^{15}$

Ante as considerações supracitadas comprova-se novamente que o existencialismo proposto pelo filósofo francês é ateu, ou seja, não existe um Deus criador responsável pela concepção do ser humano no meio em que vive.

Justificando o que foi exposto até o momento, recorrere-se novamente às lições formuladas por Jean Paul Sartre, que dispõe:

Com efeito, tudo é permitido Se Deus não existe, fica o homem, por conseguinte abandonado, já que não encontra em si nem fora de si uma possibilidade a que se apegue (...) O indivíduo é livre. Ele não apenas tem liberdade, mas é liberdade. Nós construímos tudo: até mesmo nossos valores, regras e imposições (...) O homem está condenado a ser

\footnotetext{
${ }^{14}$ SARTRE, Jean Paul. O existencialismo é um humanismo. A imaginação: Questão de método. Seleção de textos de José Américo Motta Pessanha. Tradução de Rita Correira Guedes, Luiz Roberto Salinas Forte, Bento Prado Júnior. $3^{\text {a }}$ ed. São Paulo: Nova Cultural, 1987 , p. 14.

${ }^{15}$ SANTOSA, Mônica Marcondes de Oliveira. Liberdade, Tortura e Relações com o
} Outro - "mortos sem sepultura" de Jean Paul Sartre. São Paulo: Fonte Editorial, 2013, p. 46. 
livre, condenado não porque criou a si próprio, e no entanto livre, porque uma vez lançado ao mundo, é responsável por tudo quanto fizer. ${ }^{16}$

Além do mais, constata-se através da leitura realizada, que a inexistência de um ser superior e criador faz com que seja inadmissível a hipótese do homem possuir um destino prévio, logo, ao seguir o disposto pela doutrina existencialista sartreana, observa-se que o homem simplesmente existe, sendo que sua essência consistirá em tudo aquilo que ele fizer de si ou para si.

Em complementação ao que foi exposto e segundo os ensinamentos expressos pelo filósofo francês, que ao considerar o homem como criador de sua própria liberdade, Jean Paul Sartre acaba por declarar que: "Se com efeito, a existência precede a essência, não será nunca possível referir uma explicação a uma natureza humana dada e imutável, por outras palavras, não há determinismo, o homem é livre, o homem é liberdade". ${ }^{17}$

Assim, ao analisar o que foi exposto até o momento, conclui-se que para o existencialismo sartreano o projeto de vida a ser adotado e desenvolvido pelo homem será fruto do exercício de sua liberdade, circunstância que considerará o ser humano como o criador de seu próprio mundo.

Ainda no tocante ao exercício da liberdade acima descrito, é necessário informar que para o filósofo francês tal atividade se perpetua em meio a um universo quase que inesgotável de possibilidades.

Destaca-se que dentre as possibilidades existentes encontram-se as ações, omissões, bem como toda e qualquer postura a ser desenvolvida ou omitida pelo ser humano, logo, será justamente dentre esse universo de possibilidades que o homem será formado.

Portanto, de acordo com o que foi observado até o momento, para o existencialismo sartreano, o homem não consiste em um ser predeterminado, muito pelo contrário, vez que figura como um ente pertencente ao mundo, sendo totalmente consciente do resultado a ser produzido por força de suas ações ou omissões.

\footnotetext{
${ }^{16}$ SANTOSA, Mônica Marcondes de Oliveira apud SARTRE, Jean Paul. O existencialismo é um humanismo. São Paulo: Abril Cultural, 1974, p. 15.

${ }^{17}$ Ibidem.
} 
Cumpre esclarecer que a consciência inerente ao ser humano por força das ações que desenvolve, ou ainda, que deixa de praticar, encontra-se diretamente ligada ao senso de responsabilidade vinculado ao homem.

Ao discorrer sobre a definição de responsabilidade segundo Jean Paul Sartre, Luiz Damon Santos Moutinho leciona:

Responsabilidade é tomada por Sartre no sentido de "consciência de ser o autor de um evento ou um objeto"; para usar terminologia anterior, trata-se da consciência de que a situação só existe pela liberdade; ela não é separada e anterior a mim: ela só existe por mim, exatamente na medida em que minha liberdade a colabore, fazendo-a aparecer desta ou daquela maneira. ${ }^{18}$

Diante dos ensinamentos expostos, novamente resta cristalino que a liberdade no existencialismo sartreano enseja ao ser humano um grande senso de responsabilidade, pois esse passa a perceber que o exercício de sua liberdade através das escolhas que realizará no curso de sua vida não afetará apenas a si mesmo, mas também a sociedade como um todo.

Reitera-se que para o filósofo francês, o homem no exercício da sua liberdade entende tal existência como um relacionamento do homem consigo mesmo e com o universo em que está inserido, passando a ser responsável pela condução de sua vida, mas também por toda a coletividade.

Indispensável salientar que a sensação de responsabilidade narrada causa sobre o ser humano uma imensa angústia, principalmente pelo fato de poder contar apenas consigo mesmo na tomada de decisões, sem ter como recorrer a um Deus criador para escolher, ou, ao menos indicar o caminho a ser trilhado.

Vale ressaltar que o homem não poderá escapar da angústia descrita, contudo, tal situação desconfortável não lhe impedirá de tomar decisões, já que nos moldes do que foi abordado no curso do trabalho, o

${ }^{18}$ MOUTINHO, Luiz Damon Santos. Sartre: existencialismo e liberdade. São Paulo: Moderna, 1995, p. 77. 
simples fato de permanecer estático será considerado como uma escolha, que gerará efeitos em face do responsável pela ação ou omissão, bem como sobre os demais membros da coletividade.

Insta salientar ainda, que a angústia decorrente do exercício da liberdade, que é dotada de grande carga de responsabilidade, não provém somente do fato do homem ter que eleger suas decisões de maneira individual, mas também por ter a ciência de que ao adotar um caminho, todos os demais serão extintos de seu quadro de possibilidades, circunstância que reitera o ideal de que o homem será livre para escolher e desfrutar de novas possibilidades.

Ante as informações elencadas, pode-se afirmar que o existencialismo sartreano extrapola o ideal de subjetivismo individualista, pois sustenta que as escolhas efetivadas pelo homem não serão fundadas apenas em seu exclusivo desejo, mas abarcarão toda a humanidade, que estará refém da subjetividade humana relacionada às decisões a serem tomadas por cada ente social.

Em complementação exposto, deve-se tornar claro que a presença da responsabilidade no exercício das escolhas poderá ser observada como uma espécie de condição, que de certo modo restringirá as ações a serem desenvolvidas pelo homem. Portanto, apesar do existencialismo sartreano não acreditar na figura de um Deus superior que poderia ser capaz de sancionar aqueles que tomarem decisões prejudiciais à humanidade, revela-se existente a responsabilidade, que atua como uma espécie de regramento que fará com que o homem que faz parte daquele meio social venha a conduzir suas decisões pautando-se também na maneira como o exercício de sua liberdade poderá vir a afetar os demais membros da sociedade.

Dessa maneira, a construção de valores para Jean Paul Sartre traduz-se em algo real e individual, pois a liberdade facultará ao seu detentor o exercício do querer de forma autônoma, destacando-se que o homem se encontra só, já que não poderá escolher o caminho a ser seguido através do auxílio prestado por um ser superior. Além do mais, a liberdade não consistirá em uma coisa, mas sim em um ato, que poderá ser ativo ou omissivo, marcado pela angústia inerente à tomada da decisão, vez que o homem não poderá jamais escapar de sua liberdade, que se revelará apta a impulsionar a conduta humana.

Sendo assim, conclui-se que o existencialismo criado por Jean Paul Sartre fundamenta-se basicamente no exercício do conceito de liber- 
dade formulado pelo filósofo, que acaba por entender que a existência precederá a essência, excluindo-se a presença de um Deus transcendental que seria capaz de auxiliar o homem na escolha de suas decisões, ou ainda, sancioná-lo pela eleição errada. Logo, seria o homem livre para se formar e desenvolver através do exercício da liberdade que lhe é fornecida, sem se olvidar que suas decisões serão responsabilizadas pelos efeitos que gerar a si, bem como à sociedade, que poderá em algumas hipóteses ser visualizada como um meio limitador do exercício da liberdade.

\section{CONSIDERAÇÕES FINAIS}

Através do presente estudo, foi possível analisar de maneira pormenorizada os conceitos de liberdade em Aristóteles e no existencialismo de Jean Paul Sartre.

Cumpre esclarecer que o estudo desenvolvido apresentou um breve panorama da sociedade em que ambos os filósofos estavam inseridos.

Ao se analisar o contexto social de ambos, foi possível constatar que a sociedade grega vivenciada por Aristóteles apresentava um cenário político e social em que era comum a prática da escravidão, bem como a imposição de restrições à participação nas decisões políticas a serem tomadas pela sociedade.

Portanto, segundo a doutrina aristotélica a liberdade emanaria em um plano basicamente político e social, que se desenvolveria através da prática de ações e omissões por um homem considerado livre na sociedade.

Além do mais, restou aclarado que as ações voluntárias e demais decisões eleitas pelo homem devem sempre se basear naquilo que é bom, almejando a felicidade.

Assim, o conceito de liberdade em Aristóteles permitia aos cidadãos gregos o exercício de uma interação do indivíduo com a sociedade em que se encontra inserido, destacando-se que a prática da liberdade estaria relacionada à ação moral, que de acordo com o que foi exposto, objetiva a felicidade, que seria perseguida através de ações voluntárias a serem desenvolvidas por esse titular da liberdade. 
Por sua vez, a sociedade em que Jean Paul Sartre estava inserido, não apresentava o mesmo cenário de escravidão observado no período em que viveu Aristóteles, nos moldes do que relata Miguel Reale, que sobre a evolução do conceito de liberdade, dispõe:

Quando se atinge certo grau de evolução é que se proclama, como na Revolução Francesa, que todos os homens nascem livres e iguais, afirmando-se de forma solene, e com projeção universal, aquilo que já fora proclamado por ocasião da independência norte-americana, com a Declaração de Filadélfia, que o homem vale como sujeito de direitos e deveres tão-somente pelo fato de ser homem. ${ }^{19}$

Contudo, o filósofo francês acabou por presenciar conflitos militares mundiais, bem como teve o exercício de sua liberdade plena tolhido ao ser preso em um campo de concentração nazista.

Desse modo, constata-se que Jean Paul Sartre vivenciou um período mais próximo a nossa realidade, em que a privação da liberdade através da escravidão não era tão comum, apesar de existir, de acordo com o que foi relatado, o cerceamento à liberdade por força de atuações militares.

Durante a análise da teoria existencialista sartreana, restou aclarado que para o filósofo francês a existência precede a essência, circunstância que faz com que seja excluída a existência de um Deus transcendental, que seria capaz de auxiliar o ser humano na tomada de suas decisões, ou ainda, que poderia puni-lo pela prática de uma ação ou omissão que veio a prejudicar outras pessoas.

Entretanto, é necessário reiterar que apesar do existencialismo sartreano ser ateu, o homem será responsabilizado por todas as suas ações, sendo condenado a sua própria liberdade, vez que o fato de permanecer inerte em determinada ocasião também será caracterizado como o exercício de sua liberdade.

Relevante se faz esclarecer ainda, que a inexistência de um Deus superior causa grande angústia ao ser humano, pois o detentor da

${ }^{19}$ REALE, Miguel. Lições preliminares de direito, $27^{\mathrm{a}}$ ed. São Paulo: Saraiva, 2002, p. 230. 
liberdade não terá ninguém a auxiliá-lo na escolha das decisões, destacando-se que tal angústia emana também pelo fato de que ao ser escolhido um caminho, todas as outras alternativas serão excluídas de seu rol de possibilidades, circunstância que insere o homem como plenamente livre para se desenvolver por meio do exercício de sua liberdade, sem esquecer que o ser humano sempre será responsável por suas decisões, sendo que em alguns casos a própria sociedade em que está inserido poderá ser considerada um meio limitador ao exercício de sua liberdade.

Vale ressaltar que a sociedade poderá ser observada como um meio limitador, pois ao constatar que suas ações poderão prejudicar terceiros, e que tal prejuízo poderá gerar uma sanção sobre si, o próprio contexto social poderá vir, de certa maneira, a limitar o titular da liberdade na tomada de suas decisões.

Sendo assim, através do presente trabalho, foi possível analisar o contexto histórico e social em que os filósofos alvo de análise estavam inseridos, bem como interpretar os conceitos de liberdade em Aristóteles e no existencialismo de Jean Paul Sartre.

\section{REFERÊNCIAS BIBLIOGRÁFICAS}

ARISTÓTELES. Ética a Nicômaco; Tradução do grego de António de Castro Caeiro. São Paulo: Atlas, 2009.

CHAUI, Marilena. Convite à filosofia. São Paulo: Ática, 2012.

MOUTINHO, Luiz Damon Santos. Sartre: existencialismo e liberdade. São Paulo: Moderna, 1995.

REALE, Miguel. Lições preliminares de direito, $27^{\mathrm{a}}$ ed. São Paulo: Saraiva, 2002.

SANTOSA, Mônica Marcondes de Oliveira. Liberdade, Tortura e Relações com o Outro - "mortos sem sepultura" de Jean Paul Sartre. São Paulo: Fonte Editorial, 2013.

SARTRE. Jean Paul. Entre quatro paredes. Tradução de Alcione Araújo e Pedro Hussak. São Paulo: Civilização Brasileira, 2005.

. O existencialismo é um humanismo. A imaginação: Questão de método. Seleção de textos de José Américo Motta Pessanha. Tradução de Rita Correira Guedes, Luiz Roberto Salinas Forte, Bento Prado Júnior. 3ª ed. São Paulo: Nova Cultural, 1987. 
. O ser e o nada: ensaio de ontologia fenomenológica. Tradução de Paulo Perdigão: Petrópolis, Vozes, 1998.

ZANINI, Leonardo Estevam de Assis. Direitos da personalidade: aspectos essenciais. São Paulo: Saraiva, 2011. 